\title{
Towards Hand Model with Integrated Multichannel Sensor System for Thermal Testing of Protective Gloves
}

\author{
David Kalas $^{1 *}$, Silvan Pretl1, Jan Reboun¹, Radek Soukup', Ales Hamacek \\ ${ }^{1}$ Department of Technologies and Measurement, Faculty of Electrical Engineering, University of West Bohemia, \\ 30100 Pilsen, Univerzitní 8, Czech Republic \\ * Corresponding author, e-mail: kalasd@ket.zcu.cz
}

Received: 08 October 2018, Accepted: 30 October 2018, Published online: 13 November 2018

\begin{abstract}
This paper deals with the development of a temperature sensor system consisting of multiple temperature sensors integrated into a model of a human hand and a system for data collection, processing and 3D visualization. The measuring part of the system uses temperature sensors TMP05, which enable daisy chain serial connection. The individual chains are then connected to the microprocessor. The microprocessor controls the temperature measurement and sends data to the computer, where data is processed, evaluated and visualized. The temperature sensors are mounted on flexible printed circuit boards which are placed into the human hand model and subsequently fixed by a UV curable adhesive. The model of the human hand is designed in accordance with the standard models for the production of rubber gloves and it is made on a 3D printer of polyamide PA6 filled with short carbon fibers. The final version of the system will have approximately two hundred sensors, which will be concentrated mainly in the area of fingers and back of the hand.
\end{abstract}

Keywords

sensor system, temperature measurement, 3D visualization, gloves, thermal protection

\section{Introduction}

In recent years the new clothes materials [1] and production technology [2] have been developed in the field of work and protective clothing as well as an integration of simple sensor elements directly into the fabric [3]. Currently, firefighter's gloves with the sensor for measuring temperature of distant objects [4] or a firefighter's suit for monitoring dangerous gases, temperature and relative humidity are available [5]. In connection with this development and the new trend of integrating electronics to the clothes, there is also a requirement for high-quality thermal testing of protective clothing, especially for clothes exposed to high temperatures. Such thermal testing systems are only available at few leading workplaces. However, those systems use a limited amount of temperature sensors in the hand area and they are not particularly suitable for testing of protective gloves [6].

Currently, there does not exist any commercially available test system which would be able to measure detail distribution of real temperatures inside the protective gloves. Currently used test and measurement protocols usually work with a limited amount of sensors [7-9] or with only the plain textile sandwich made of basic glove's materials [10]. These tests cannot reliably identify and locate critical areas of the glove. They are unable to locate minor structural changes because they integrate the temperature from a large area. The thermal protection of gloves depends both on the construction of the glove (types and positions of seams, number of parts and layers of gloves) [11] and on materials, which are used only on particular parts of a glove (such as foam fillings, reinforcements and reflective trims).

In this paper, the development of a novel technology for thermal testing of gloves is described. This whole system consists of a device with a radiant heat source, a 3D model of human hand with integrated temperature sensors and software for data processing and data visualization. The sensor system should be used mainly for testing of firefighter's gloves and help optimize the glove construction to reduce the number of skin burn injuries and heat stress [12] in the area of the hand. Increased thermal protection should be achieved by developing new gloves as well as by testing gloves during their use and by comparing their thermal insulating properties with new gloves. 


\section{Experimental}

At the beginning of R\&D, we determined together with the glove manufacturer four main requirements for the sensor system: minimum of 200 temperature measurement positions for detail measuring of the temperature distribution inside the glove, measuring period equal or less than 2 seconds, an accuracy of measurement of $\pm 1^{\circ} \mathrm{C}$ and size of individual temperature sensor max. $2.5 \mathrm{~mm} \times 2.5 \mathrm{~mm}$. Based on these requirements the suitable sensors and a microprocessor were chosen and the whole architecture of the system was designed.

\subsection{The architecture of the sensor system}

Based on the requirements, the TMP05 sensor from Analog Devices with dimensions of $2.2 \mathrm{~mm}$ x $2.4 \mathrm{~mm}$ (with leads) was selected [13]. The key features of this sensor include the possibility of serial connection ("daisy chain"), measuring time of approximately $120 \mathrm{~ms}$ depending on the specific measured temperature and the total measurable temperature range from $-40{ }^{\circ} \mathrm{C}$ to $+150{ }^{\circ} \mathrm{C}$. The accuracy of the measurement is $\pm 0.5^{\circ} \mathrm{C}$ at $25^{\circ} \mathrm{C}$ and $\pm 1{ }^{\circ} \mathrm{C}$ at $75^{\circ} \mathrm{C}$. The sensor output provides a pulse width modulated (PWM) signal.

In view of the fact that sensors TMP05 were chosen, we used a serial-parallel structure of the measurement system. The maximum number of sensors connected in individual series was set to 12 to meet the sampling period requirement. Based on this, the microprocessor had to be capable of parallel signal processing of signals from at least 17 sensors serial chains to meet the number of sensors requirement. The microprocessor STMicroelectronics STM32F446RE with 12 counters and 32 input capture channels have been selected. They are used for detecting individual edges of the PWM output signal from temperature sensors chains. Each edge is assigned its relative timestamp and based on this, the length of the high and low signal levels is calculated. The temperature is then calculated by the equation, Eq. (1).

Temperature $=421-\left(751 x \frac{T_{H}}{T_{L}}\right)$,

where $T_{H}$ and $T_{L}$ is high and low signal level duration, respectively.

The measurement is triggered by a start pulse at a high level with a specific pulse width from $20 \mathrm{~ns}$ to $25 \mu \mathrm{s}$, which is generated by the microprocessor. This start signal is sent in parallel to every sensor chain in order to start the measurement at the same time. Once the sensor detects the start pulse, it initiates the measurement. The result of the measurement and the new start pulse for next sensor are inserted at the end of the daisy chain PWM signal frame. This means, that the location of each individual sensor is determined by the sequence of pulses at the output of the whole chain. The time of the measurement depends both on the number of sensors in the chain and the measured temperature (Fig. 1) [14].

The control system in the computer uses serial communication with a USB converter. The architecture of the whole system for temperature measurement inside the glove during thermal testing is shown in Fig. 2.

\subsection{The realization of sensor elements and model of a human hand}

The first prototypes of flexible sensor chains were realized using conventional flexible printed circuit board technology on double-sided polyimide (PI) substrate (Kapton, $100 \mu \mathrm{m})$ with $18 \mu \mathrm{m}$ copper foils, with ENIG surface finish and $10 \mu \mathrm{m}$ solder mask. The first prototypes of flexible sensor chains were designed specifically for the middle

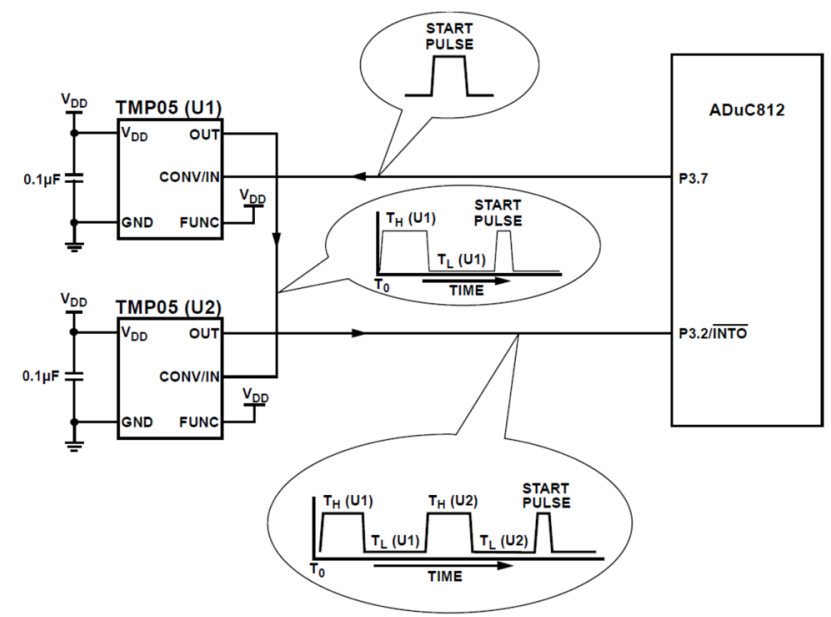

Fig. 1 Typical daisy-chain application circuit and output signal format [12].

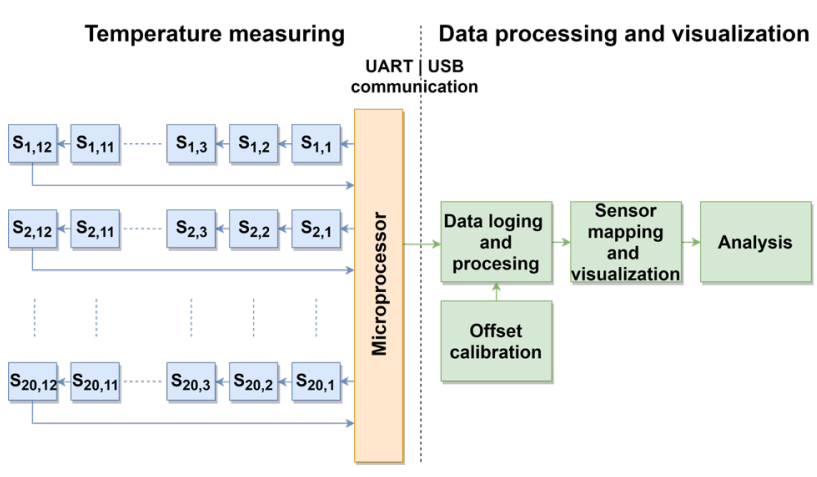

Fig. 2 Block diagram of the sensor system 
finger and had either 12 sensors (placed on the left and right sides and on the tip of a finger) or 11 sensors (placed on the front and rear side of the finger) (Fig. 3). The characteristic impedance of the signal lines was designed to be $50 \Omega$. The micro-coaxial connectors and coaxial cables were used for signal connection with the microprocessor. Both flexible sensor chains were mounted into the recessed grooves along all four sides of the finger and they overlapped each other at the tip of the finger.

The physical human hand model was fabricated with the high-resolution 3D printer (Markforged Mark Two). Polyamide PA6 filled with short carbon fibers (Markforged Onyx) was used for printing (Fig. 4). The 3D shape of the human hand model was designed according to the standard models of hand used for the production of rubber gloves. The model consisted of several parts that

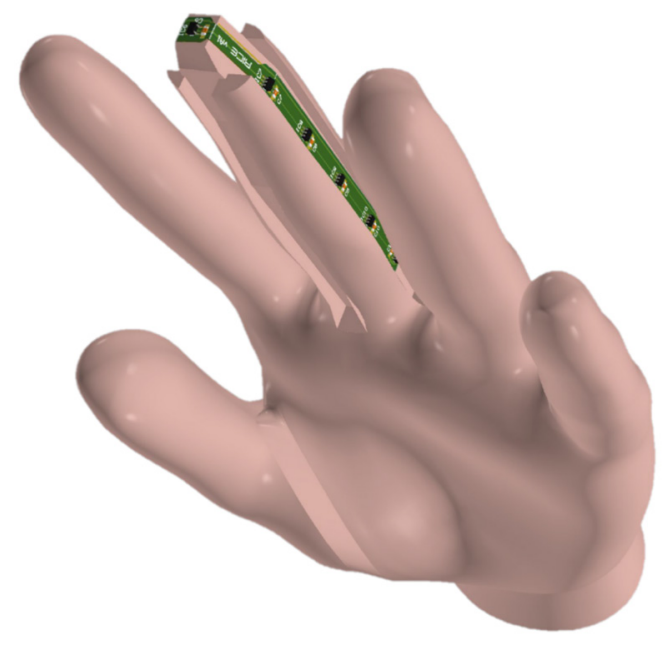

Fig. 3 Finger with flexible PCB.
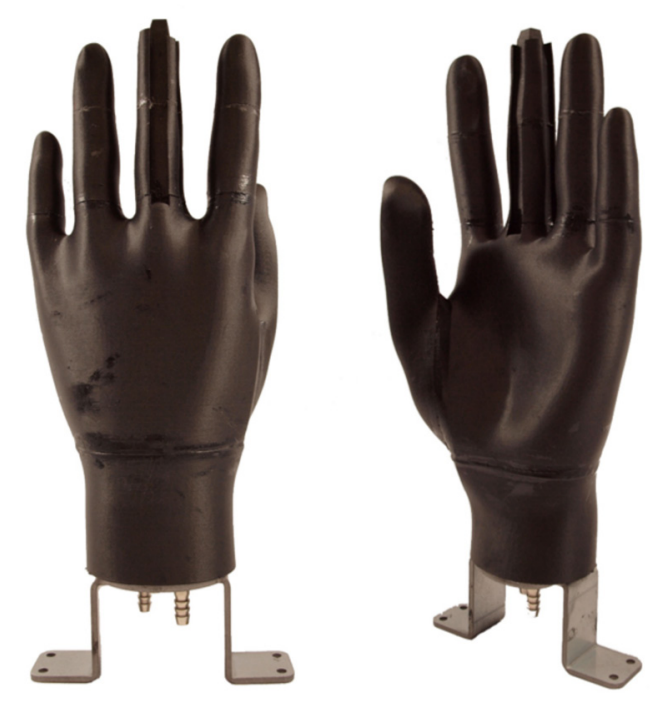

Fig. 4 Human hand model. were bonded together by the two-part hybrid adhesive Loctite HY 4090 with temperature resistance of $150{ }^{\circ} \mathrm{C}$, vibration and temperature shock resistance and with high moisture resistance. The primer Loctite SF 7239 was used to increase the adhesion. On the surface of the hand model, there were grooves for integration of the flexible printed circuit boards (FPCBs) with sensors. The acrylic-based, UV curable and high viscosity adhesive Loctite AA 3926 was used for the fixation of FPCBs. This adhesive was selected because it does not cure during the precise placement of FPCBs in the grooves. When the FPCBs was embedded, the grooves were filled with polyurethane (PU) thixotropic material in order to increase both mechanical protection and unification of the surface.

\subsection{Data processing and visualization}

Software application for the temperature measurement control, data processing and visualization was developed in LabVIEW. The application is based on the state machine principle with three independent loops: Measurement, Visualization, and Analysis. The "Measurement" loop controls sampling period and the measurement time, calibration of the temperature offset and the data recording to the CSV file. The "Visualization" loop renders a heat map on the surface of the 3D model of the hand (Fig. 5). It is possible to zoom, turn or shift the $3 \mathrm{D}$ visualization as well as the displayed temperature range. The visualization can be presented step by step or continuously. The last loop "Analysis" monitors the time-temperature profile at the defined position of the human hand model, where it also determines the minimum and maximum temperatures and their differences. Data can be filtered using a moving average with optional length of the window (Fig. 6).

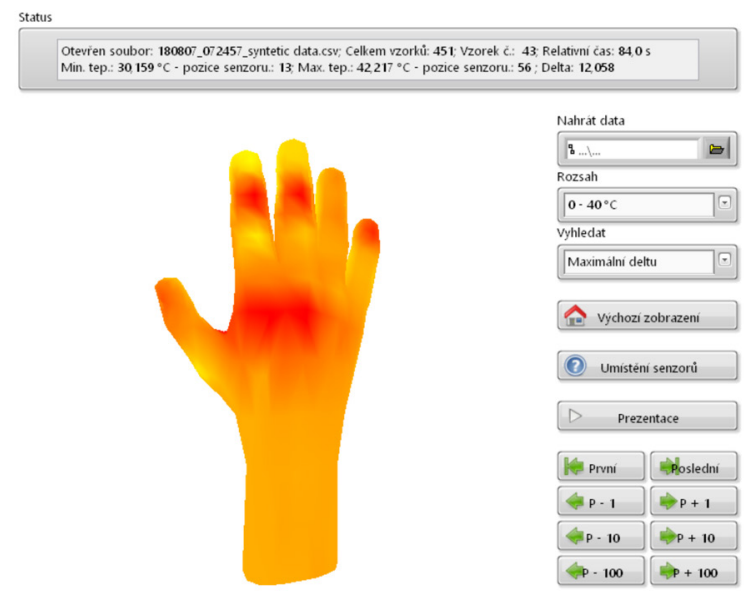

Fig. 5 Visualization of temperature distribution. 

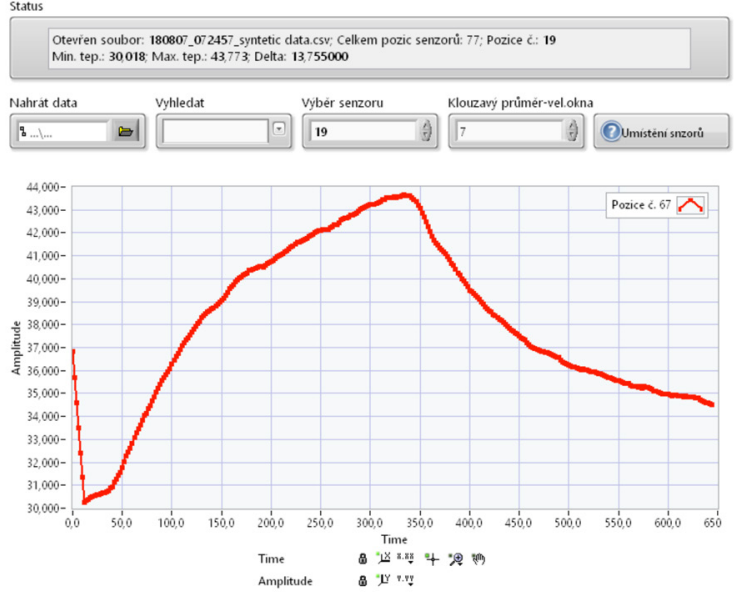

Fig. 6 Analysis of temperature data.

\section{Results}

\subsection{Temperature characterization of sensors}

The prototypes of FPCBs with temperature sensors were tested in a calibration thermostatic oil bath Lauda PJL12C with the silicone oil. Temperature stability of the bath is $0.01{ }^{\circ} \mathrm{C}$. Firstly, we investigated the temperature measurement error at a nominal temperature of $25{ }^{\circ} \mathrm{C}$. The measurement error for each sensor was calculated as the difference of its average temperature reading against the temperature in the thermostatic oil bath. As you can see in the graph (Fig. 7), the majority of sensors measured temperature higher than $25^{\circ} \mathrm{C}$. Of the 92 sensors $67 \mathrm{fit}$ in the tolerance $\pm 0.5^{\circ} \mathrm{C}$, which is indicated by the manufacturer at the nominal temperature of $25^{\circ} \mathrm{C}$.

Based on these results of the temperature offset error was corrected. The correction was used for all following measurements. However, the sensors with temperature error higher than $\pm 0.7^{\circ} \mathrm{C}$ had to be omitted because as the temperature increased, their error was increasing significantly when compared to sensors within the tolerance $\pm 0.7^{\circ} \mathrm{C}$. Of the 92 sensors 7 were omitted. This selection process will have to be done every time before mounting of FPCBs to grooves of the human hand model.

The second step of temperature sensor characterization was determination of the measurement accuracy within a wide range of temperatures. The test was performed after the calibration described above. We used a stepwise temperature profile growing from $10{ }^{\circ} \mathrm{C}$ to $90{ }^{\circ} \mathrm{C}$ with a $10{ }^{\circ} \mathrm{C}$ step increase each hour and then decreasing from $90{ }^{\circ} \mathrm{C}$ back to $10{ }^{\circ} \mathrm{C}$, in the same manner. This profile was repeated three times in total (Fig. 8).

The temperature measurement errors for each temperature step were calculated as the difference of their

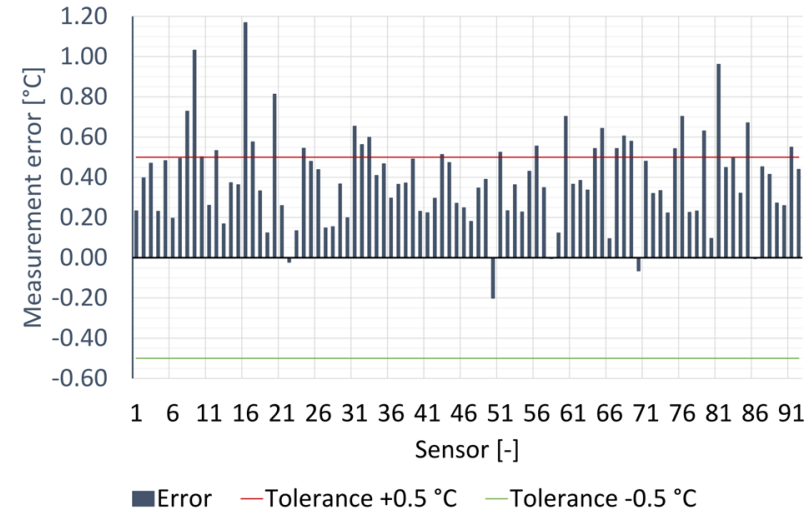

Fig. 7 Temperature measurement error.

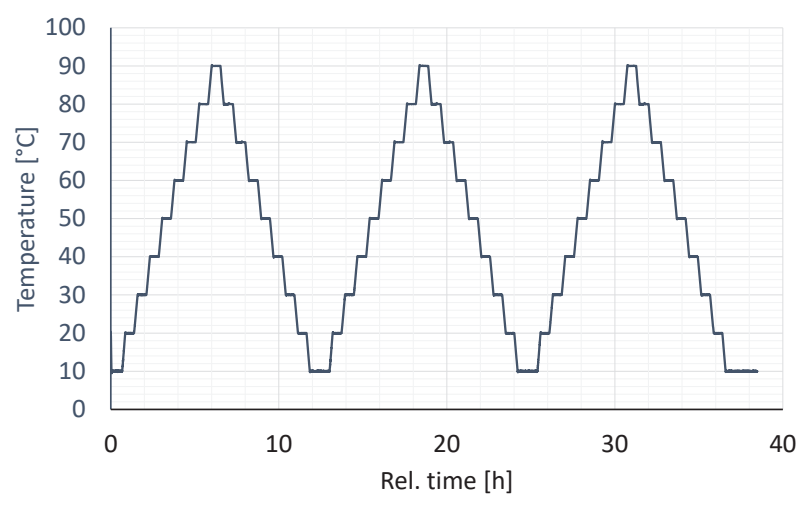

Fig. 8 Temperature profile

average reading temperature from all sensors against the temperature in the thermostatic oil bath at each individual constant temperature level (last 30 minutes of each step were taken into consideration). The average measurement error from $20^{\circ} \mathrm{C}$ to $90^{\circ} \mathrm{C}$ was $0.15^{\circ} \mathrm{C}$ and error at $10^{\circ} \mathrm{C}$ was $0.4^{\circ} \mathrm{C}$. The largest absolute measurement errors were $+1.095^{\circ} \mathrm{C}$ and $-0.9{ }^{\circ} \mathrm{C}$ (Fig. 9).

After the sensor accuracy measurement, the dynamic response of sensors, which were placed and fixed by the adhesive in the grooves of the human finger model, was tested. The grooves were filled with a different amount of

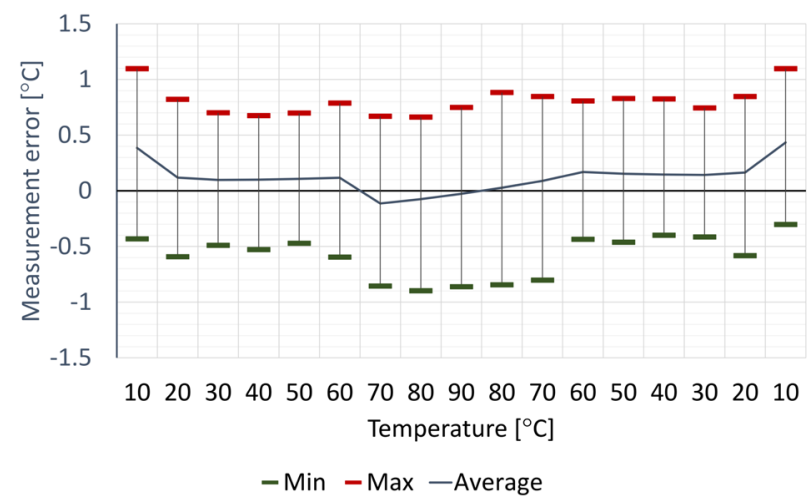

Fig. 9. Accuracy of measurement after calibration at $25^{\circ} \mathrm{C}$. 
polyurethane material. The dynamic response was measured in three setups: sensors uncovered, partly-covered and fully-covered. This means without the filling, surface of sensors not covered by filling material and surface of sensors below the layer of filling material, respectively. The measurement was performed in the open air with the ambient temperature of $25{ }^{\circ} \mathrm{C}$ for 30 minutes and subsequently, the models of the finger with sensor elements were immersed in the oil bath with temperature $80{ }^{\circ} \mathrm{C}$ for the same amount of time (Fig. 10).

The temperature rise-time was calculated as a mean of time from the moment of immersion to reaching the measured temperature $80^{\circ} \mathrm{C}$. Secondly, the temperature falltime was calculated from the removing of the elements from the oil bath to reaching the measured temperature $25^{\circ} \mathrm{C}$. The values from individual measurement cycles were averaged (Table. 1).

Based on these results the amount of filling material need to be decreased and consequently decrease the thermal capacity. The surface of the sensors has to remain uncovered to achieve the best dynamic responses.

\subsection{Characterization of textile sandwiches}

Measurement with planar textile sandwiches is more suitable for detailed characterization of individual inhomogeneities and defects of gloves (seams, foam fillings etc.).

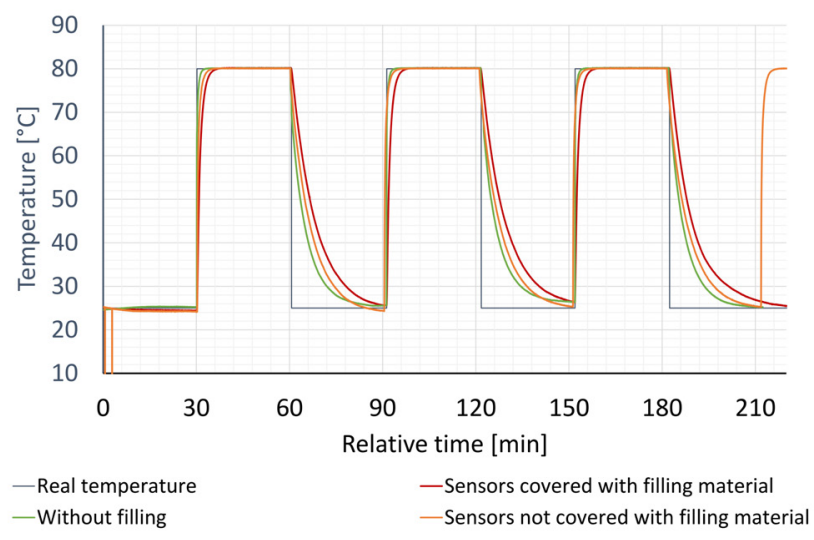

Fig. 10 Dynamic response of the system.

Table 1 Dynamic response of the system.

\begin{tabular}{lcc}
\hline Level of filling & $\begin{array}{c}\text { Time of rise }[\mathrm{s}] \\
25^{\circ} \mathrm{C} \rightarrow 80{ }^{\circ} \mathrm{C}\end{array}$ & $\begin{array}{c}\text { Time of fall }[\mathrm{s}] \\
80^{\circ} \mathrm{C} \rightarrow 25^{\circ} \mathrm{C}\end{array}$ \\
\hline $\begin{array}{l}\text { Without filling } \\
\text { Sensors not covered } \\
\text { with the filling } \\
\text { material }\end{array}$ & 161 & 1232 \\
$\begin{array}{l}\text { Sensors covered with } \\
\text { the filling material }\end{array}$ & 320 & 1496 \\
\hline
\end{tabular}

Testing of the behaviour of textile sandwiches will allow to select a suitable measurement method for the 3D sensor system for the gloves testing. The textile sandwiches with dimensions $10 \mathrm{~cm}$ x $15 \mathrm{~cm}$ were stretched in a frame and exposed to radiant heat source with thermal power of $5 \mathrm{~kW} / \mathrm{m}^{2}$ at a distance of $50 \mathrm{~cm}$. There were available fourlayer textile sandwiches (Fig. 11) in two versions (Table 2). These sandwiches consisted of commonly used textiles for firefighter's gloves, first protective layer Nomex (1), aramid nonwoven fabric layer (2), polyurethane membrane (3) and aramid lining with increased mass (4).

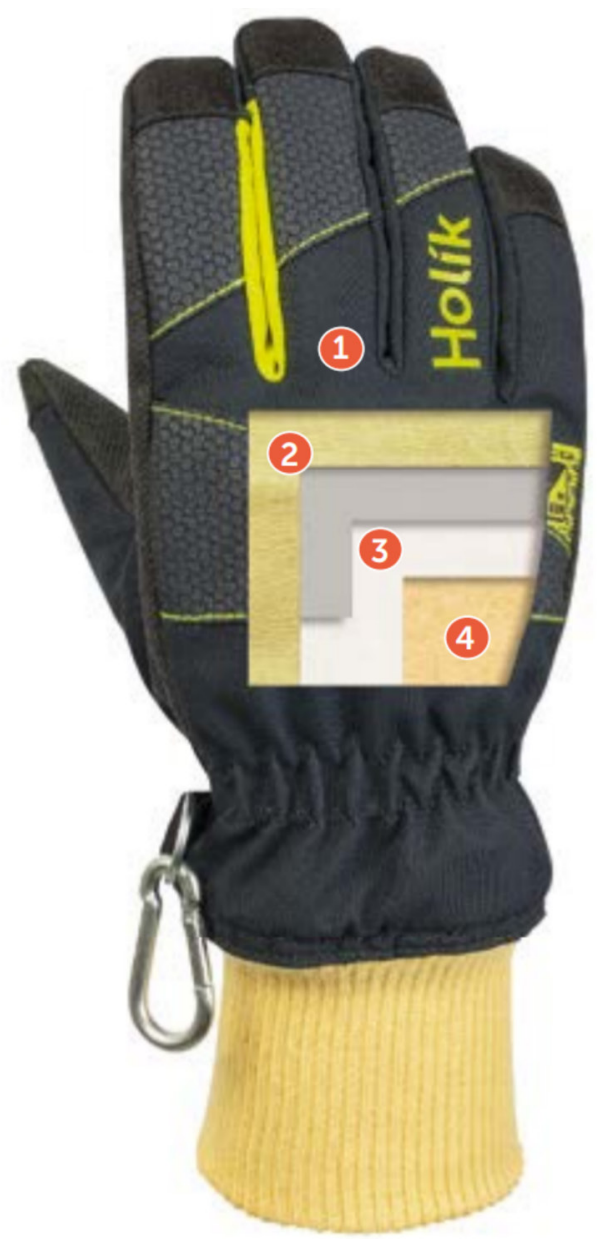

Fig. 11 Basic textile sandwich for firefighter's gloves [15].

Table 2 Versions of textile sandwiches.

\begin{tabular}{lll}
\hline Layers & sample A & sample B \\
\hline $\begin{array}{l}\text { 1 Nomex } \\
\text { protective layer }\end{array}$ & $\begin{array}{l}\text { one seam in the } \\
\text { middle of the layer, } \\
\text { first two layers } \\
\text { nonwid } \\
\text { layer }\end{array}$ & $\begin{array}{l}\text { one seam in the } \\
\text { middle of the layer, } \\
\text { first two layers } \\
\text { sewed together }\end{array}$ \\
$\begin{array}{lll}\text { P PU membrane } \\
\text { w Aramid lining }\end{array}$ & $\begin{array}{l}\text { without seams } \\
\text { one seam in the } \\
\text { middle of the layer }\end{array}$ & without seams \\
\hline
\end{tabular}


The surface temperature of textile sandwiches was measured by a thermal camera FLIR i7. The thermal camera was placed behind the textile sandwich during thermal exposure. The seams were the coldest at the beginning of the expose due to the overlap of the individual layers in the seam region and they began to heat up approximately in 2 minutes from the beginning of the measurement. The greatest temperature difference between the seam area and the seamless area was detected approximately $50 \mathrm{sec}-$ onds after the end of the exposure (Fig. 12 and Table 3).

\section{Discussion}

The aim is to develop a testing system for evaluating of thermal insulation of protective gloves, temperature characterization of the temperature sensors and testing of basic textile sandwich samples. Protective gloves are an indispensable part of safety equipment and there is no system for real testing of the glove thermal insulation, for example after the multiple thermal exposures.

Selected temperature sensors were tested in high accuracy thermostatic oil bath which is intended for the calibration of temperature sensors. The accuracy of the temperature measurement of individual sensors was measured with the stepwise temperature profile. Textile sandwiches were measured with an infrared thermal camera during and after the end of the thermal exposure.

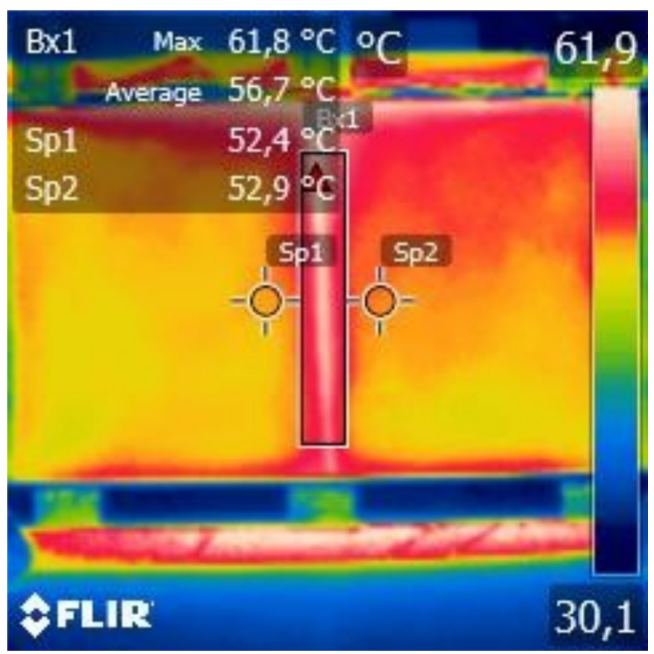

Fig. 12 The surface temperature of the textile sandwich (Sample A).

Table 3 Dynamic response of the system.

\begin{tabular}{llll}
\hline Sample & $\begin{array}{l}\text { Seamless } \\
\text { area } \\
\text { temperature } \\
{\left[{ }^{\circ} \mathrm{C}\right]}\end{array}$ & $\begin{array}{l}\text { Max.of the } \\
\text { temperature in the } \\
\text { seam area/area } \\
\text { width }\left[{ }^{\circ} \mathrm{C} / \mathrm{mm}\right]\end{array}$ & $\begin{array}{l}\text { The average } \\
\text { temperature in the } \\
\text { seam area/area } \\
\text { width }\left[{ }^{\circ} \mathrm{C} / \mathrm{mm}\right]\end{array}$ \\
\hline A & 53 & $62 / 3$ & $57 / 10$ \\
B & 49 & $51 / 15$ & $49 / 15$ \\
\hline
\end{tabular}

In the next step of the sensor system development, the amount of material of the human hand model should be decreased. This will reduce response time and improve the ability to detect the thermal insulation damage of the protective gloves. The flexible printed circuit boards with the temperature sensors need to be designed using materials and layout with a minimal thermal conductivity. This design and layout must not have an impact on signal integrity. First tests of the whole sensor system and its ability to detect the thermal insulation damage will be realized with planar textile sandwiches. These tests should reveal the effect of the varied air gap between the textile sandwich and the model with integrated sensor elements and also the behaviour of individual defects and inhomogeneities of the gloves. The final phase of this project will be focused on the specification and definition of an appropriate methodology of the measurement. The final version of the sensor system will have more than two hundred sensors, which will be concentrated mainly in the area of fingers and the back of the hand. The human hand model will be designed for the most typical size and shape of the gloves.

\section{Conclusion}

The work was focused on the novel technology for thermal insulation testing of protective gloves based on an artificial hand model with integrated temperature sensors. This system is going to help the development of new gloves and also the testing of used gloves, which have already been exposed to high temperatures. The main aim of this work is to optimize the construction of protective gloves to reduce the risk of skin burns.

The human hand model was designed and fabricated by a 3D printer. Within the scope of this particular work, the installation of flexible printed circuit boards with temperature sensors into the grooves on the fingers of the artificial hand was tested. The grooves were subsequently filled with encapsulation material to increase the mechanical protection of sensors and these prototypes were then tested in the thermostatic oil bath using multichannel measurement of temperature sensors. The software for the data processing, evaluation and visualization was designed and tested using real data.

In addition to testing the artificial hand model, samples of basic textile sandwiches were exposed to the radiant heat source and analyzed using a thermal camera. A significant effect of seams on heat transfer through a textile sandwich was found. 


\section{Acknowledgement}

The project presented in this article is supported by the Ministry of Industry and Trade under the Glovetech, project No. CZ.01.1.2.0.15_019/0004628 and by the Student

\section{References}

[1] Barbeau, C., Lozier, F., Stéphane, R. "Firefighter protective hood and gloves with regenerated cellulose fiber", Canada, Patent US2018020/7453 A1., 2018.

[2] Horrocks, A. R., Anand, S. C. "Handbook of technical textiles", 2nd ed., Elsevier, Amsterdam, Netherlands, 2016. https://doi.org/10.1016/C2015-0-01011-5

[3] Song, G., Mandal, S., Rossi, R. M. (eds.) "Thermal Protective Clothing for Firefighter", 1st ed., Elsevier, Amsterdam, Netherlands, 2016.

https://doi.org/10.1016/B978-0-08-101285-7.00001-0

[4] Pekar, T., Mlckov, M., Ponizilova, C., Blecha, T., Hamacek, A., Kaspar, P., Reboun, J., Soukup, R., Baxa, M., Brasna, V. "Protective glove, especially for firefighters", Czech Republic, Patent EP3315037A1, 2016.

[5] Soukup, R., Blecha, T., Hamacek, A., Reboun, J. "Smart textile-based protective system for firefighters", In: Proceedings of the 5th Electronics System-integration Technology Conference (ESTC), Helsinki, Finland, 2014, pp. 1-5. https://doi.org/10.1109/ESTC.2014.6962821

[6] Mandal, S., Camenzind, M., Annaheim, S., Rossi, R. M. "Evaluation of heat and flame protective performance of clothing using manikins", In: Nayak, R., Padhye, R. (ed.) Manikins for textile evaluation, 1st ed., Elsevier, 2017, pp. 199-223.

https://doi.org/10.1016/B978-0-08-100909-3.00009-1

[7] Mrugala, D., Ziegler, F., Kostelnik, J., Lang, W. "Temperature Sensor Measurement System for Firefighter Gloves", Procedia Engineering, 47, pp. 611-614, 2012. https://doi.org/10.1016/j.proeng.2012.09.221

[8] Hummel, A., Barker, R., Lyons, K., Deaton, A. S., MortonAslanis, J. "Development of Instrumented Manikin Hands for Characterizing the Thermal Protective Performance of Gloves in Flash Fire Exposures", Fire Technology, 47(3), pp. 615-629, 2011. https://doi.org/10.1007/s10694-010-0190-9
Grant Agency of the University of West Bohemia in Pilsen, grant No. SGS-2018-016 "Diagnostics and Materials in Electrical Engineering".

[9] Hummel, A., Barker, R., Lyons, K. "Skin Burn Translation Model for Evaluating Hand Protection in Flash Fire Exposures", Fire Technology, 50(5), pp. 1285-1299, 2014. https://doi.org/10.1007/s10694-013-0336-7

[10] European Committee for Standardization "EN 420:2003+A1:2009: Protective gloves. General requirements and test methods", 2003.

[11] Matusiak, M., Kowalczyk, S. "Thermal-Insulation Properties of Multilayer Textile Packages", AUTEX Research Journal, 14(4), pp. 299-307, 2014. https://doi.org/10.2478/aut-2014-0030

[12] O’Brien, C., Blanchard, L. A., Cadarette, B. S., Endrusick, T. L., Xu, X., Berglund, L. G., Sawka, M. N. Hoyt, R. W. "Methods of Evaluating Protective Clothing Relative to Heat and Cold Stress: Thermal Manikin, Biomedical Modeling, and Human Testing", Journal of Occupational and Environmental Hygiene, 8(10), pp. 588-599, 2011. https://doi.org/10.1080/15459624.2011.613291

[13] Analog Devices INC. "TMP05/TMP06: $\pm 0.5^{\circ} \mathrm{C}$ Accurate PWM Temperature Sensor in 5-Lead SC-70", [pdf] 2012, Available at: http://www.analog.com/media/en/technical-documentation/datasheets/TMP05_06.pdf [Accessed: 02 October 2018]

[14] Kalas, D., Pretl, S., Reboun, J., Soukup, R., Hamacek, A. "Sensor System for Testing the Level of Thermal Protection of Protective Gloves", In: 2018 41st International Spring Seminar on Electronics Technology (ISSE), Zlatibor, Serbia, 2018, pp. 1-5. https://doi.org/10.1109/ISSE.2018.8443704

[15] Holík International s.r.o., "Protective gloves for firefighters", [pdf] Catalog, 2017, Available at: http:/www.holik-international.cz/ download/2018/holik_cat_fire\&rescue.pdf [Accessed: 08 October 2018] 